\title{
Los principios de la Conciliación y la Ley No 26872
}

Javier La Rosa Calle

\section{Aspectos generales}

Uno de los temas relevantes de la conciliación viene a ser sus principios, asumiendo que los mismos son aquellos aspectos estructuradores y orientadores de determinada institución jurídica.

La Ley No26872 o Ley de Conciliación -en adelante la Ley- enumera en su artículo $2^{\circ}$ nueve principios éticos: equidad, veracidad, buena $\mathrm{fe}$, confidencialidad, imparcialidad, neutralidad, legalidad, celeridad y economía los cuales, a su vez, son desarrollados en el Reglamento de dicha norma (Decreto Supremo No 001-98-JUS) -en adelante el Reglamento-. Es propósito del presente artículo hacer un comentario sobre cada uno de estos principios.

Sin embargo, antes de efectuar esta labor, cabe señalar una primera apreciación general sobre la manera como la Ley aborda este tema, y nos referimos al hecho de que se englobe como principios de la conciliación a algunas figuras más propias del procedimiento judicial, como sería el caso de la buena fe, celeridad y economía. O también que se mencione como principios a la legalidad y veracidad, que en nuestra opinión vendrían a ser, más propiamente, condiciones necesarias para el desarrollo de la conciliación. Sobre estos aspectos, volveremos más adelante.

Un segundo aspecto a señalar es que se haya omitido toda mención al principio de simetría de poderes o empoderamiento, ${ }^{1}$ el cual incluso

1 La palabra empoderamiento proviene de la palabra inglesa empowerment que significa conferir poder. 
ha tenido reconocimiento normativo en el Código Procesal Civil (artículo VI del Título Preliminar referido al principio de socialización del proceso) para los procesos civiles. También sobre esto nos explayaremos más adelante.

\section{Principios de la conciliación}

\subsection{Equidad}

El Reglamento desarrolla brevemente este principio, cuando señala que la equidad «debe ser concebida como el sentido de justicia aplicada al caso particular, materia de la conciliación". Al respecto Ormachea señala que el objetivo de la conciliación es arribar, eventualmente, a un acuerdo que sea percibido como justo, equitativo y duradero por las partes. $^{2}$

Es decir, se trata de aplicar la noción de justicia al eventual acuerdo, no solamente desde el punto de vista del conciliador sino fundamentalmente, desde el punto de vista de las partes. Con lo cual ingresamos al tema del acuerdo satisfactorio, es decir, cuándo podemos hablar de un acuerdo cualitativamente aceptable para las partes. Al respecto cabe anotar que no basta que el resultado - el acuerdo - sea percibido como beneficioso por las partes, sino que además es importante el grado de satisfacción que las partes hayan obtenido durante el desarrollo de la audiencia de conciliación.

Por otro lado, si bien la conciliación es el resultado de lo que las partes decidan, ello no quiere decir que el conciliador deba aceptar todo tipo de acuerdos, sobre todo si en ellos se evidencian soluciones inequitativas o injustas para una o más partes. Por lo cual, en principio, el conciliador tiene la facultad de decidir algunas de las siguientes opciones:

1. Señalar a las partes su imposibilidad de seguir conduciendo la audiencia de conciliación sin mayores explicaciones.

2 Iván Ormachea Choque. Análisis de la Ley de Conciliación Extrajudicial. Lima, Cultural Cuzco, 1998, p. 28. 
2. Señalar a las partes su imposibilidad de seguir conduciendo la audiencia de conciliación brindando las explicaciones a las partes.

3. Informar a las partes lo que como conciliador piensa del acuerdo.

4. Informar a las partes lo que como conciliador piensa del acuerdo y además proponer alguna solución al problema encontrado.

Debe mencionarse que lo señalado anteriormente tiene recepción normativa en el artículo $21^{\circ}$ de la Ley, así como en el artículo $32^{\circ}$ del Reglamento, cuando señalan que el conciliador tiene la libertad de acción para conducir una audiencia según los principios señalados en la misma norma legal, con los límites del orden público, las buenas costumbres y la ética.

\subsection{Neutralidad}

La referencia que se hace en el Reglamento a este principio está vinculada al tema de la imparcialidad, señalando que ambos principios son garantías de seguridad y justicia, donde la intervención del conciliador durante el procedimiento de conciliación será sin identificación alguna con los intereses de las partes.

En el Reglamento se sigue la tendencia de ver como sinónimos a la imparcialidad y a la neutralidad, sin embargo, consideramos que ambas figuras son principios distintos, por lo que el Reglamento estaría confundiéndolas.

En este sentido, la neutralidad es la inexistencia de vínculo entre el conciliador y las partes, ello con el propósito de salvaguardar algún conflicto de intereses que pueda surgir entre el o los usuarios de los servicios de conciliación y el conciliador a cargo de la audiencia. ${ }^{3} \mathrm{De}$ producirse esta vinculación, inmediatamente el conciliador deberá retirarse de la conducción del procedimiento conciliatorio, en la medida que su neutralidad pueda verse comprometida.

Más allá de esta discusión teórica, es en la práctica donde este principio ha merecido algunas críticas. Lederach sostiene que uno de los valores que caracterizan a la mediación -entiéndase conciliación- en países como Estados Unidos y Canadá es una legitimidad ganada por

3 Christopher Moore, El proceso de mediación. Buenos Aires, Granica, 1995, p. 46. 
la vía de la neutralidad, a diferencia de realidades culturales como la de nuestros países, donde la legitimidad es muchas veces producto de la confianza que se tiene en el tercero. ${ }^{4}$

Un ejemplo de esta situación vendría a ser el caso de los jueces de paz, cuando actúan como conciliadores, quienes, por lo general, intervienen en circunscripciones territoriales pequeñas, en las cuales tienen con las partes, por obvias razones, vinculaciones ya sea de índole parental o amical, lo cual les brinda la legitimidad necesaria para promover un acuerdo que las partes acepten y luego estén dispuestas a cumplir. Por lo cual, en estricto sentido, si aplicáramos el principio de neutralidad, estas personas estarían descalificadas para desempeñarse como conciliadores.

\subsection{La imparcialidad}

Está referida a la ausencia de conductas, hechos o palabras por parte del conciliador que puedan hacer suponer a las partes que se está favoreciendo a una de ellas. Según Ormachea es un estado mental que exige que el conciliador, durante el desarrollo de sus servicios, mantenga una postura libre de prejuicios o favoritismos a través de acciones o palabras.

También señala que la imparcialidad significa que el conciliador no desempeñará un papel adversarial durante el procedimiento conciliatorio. $^{5}$

Este principio es fundamental para lograr uno de los valores más preciados durante la audiencia de conciliación: la confianza o cooperación. Es decir, en la medida que las partes perciban al tercero conciliador como que no está favoreciendo impropiamente a una de las partes, estarán dispuestas a cooperar para brindar la información necesaria y trabajar conjuntamente en el logro de soluciones satisfactorias. Moore señala que la prueba final de la imparcialidad del conciliador está en las partes, quienes irán cooperando según como vayan percibiendo a su conciliador. ${ }^{6}$

4 Juan Pablo Lederach. Enredos pleitos y problemas. Guatemala, Ediciones SEMILLA, 1992, p. 81

5 Iván Ormachea Choque. Op. cit. p. 30

6 Christopher Moore. Op. cit. p. 46 
Por otro lado, el hecho de que un conciliador deba ceñirse estrictamente a este principio, no quiere decir que no vaya a tener opinión sobre el caso que está abordando, lo que se quiere es que el tercero sepa diferenciar, y además evidenciar ante las partes, que es capaz de separar sus opiniones personales de lo que piensan las personas que están reunidas ante él. De no poder mantenerse esta situación, es mejor que el conciliador se abstenga de seguir conduciendo la audiencia.

\subsection{La confidencialidad}

Además de ser uno de los principios más importantes de la conciliación, es una de las características que nos permite establecer diferencias respecto al proceso judicial, que por esencia es público. En el caso de la conciliación, los actos llevados a cabo mientras dure el procedimiento deben efectuarse en estricta privacidad, con la sola participación de los directamente involucrados en la situación conflictiva.

Se justifica esta privacidad en el hecho de que así se puede alentar a que las partes desarrollen un amplio intercambio de opiniones y de informaciones de una manera franca y abierta. $Y$ es que un requisito ineludible para las partes y el conciliador es que puedan comunicarse con total libertad, ya que el conciliador podría solicitar información y hacer preguntas que no serían contestadas si existiera el peligro de su utilización posterior fuera de contexto. ${ }^{7}$ También se argumenta que las partes pueden requerir protección frente a los abusos de aquellos que utilicen el procedimiento conciliatorio exclusivamente para obtener información de sus oponentes, o para tantear cuál es su postura y hasta dónde están dispuestos a hacer concesiones. ${ }^{8}$

En esta orientación se sostiene que sin confidencialidad la confianza de las partes en el conciliador se debilita, la comunicación se retrae, la exploración de opciones y alternativas se hacen dificultosa y las posibilidades de conducir el proceso hacia un acuerdo se alejan. ${ }^{\text {? }}$

La confidencialidad no solamente se refiere a lo que las partes puedan haber señalado durante la audiencia de conciliación, sino que abar-

7 Adriana Schiffrin. «La mediación: aspectos generales». En: Julio Gottheil y Adriana Schiffrin. Mediación: una transformación en la cultura, Buenos Aires, Paidós, 1996, p. 46.

8 Linda R. Singer. Resolución de conflictos. Paidós, Barcelona, 1996, p. 232.

9 Roque Caivano. Negociación, Conciliación y Arbitraje. Lima, Apenac, 1998, p. 135. 
ca también lo que le puedan haber dicho al conciliador en reuniones previas a la audiencia o en las reuniones por separado que se lleven a cabo en plena audiencia. Incluso, se sostiene que el resultado de la conciliación también debería mantenerse en reserva, ello con el propósito de evitar una publicidad dańosa del acuerdo que intente generar un "precedente" ${ }^{10}$.

Es decir, en la medida que la información vertida durante la audiencia de conciliación es confidencial, la misma no podrá ser usada en ningún proceso judicial o de otra naturaleza, debiendo el conciliador negarse a testificar, salvo que las partes lo autoricen expresamente.

Tal es la importancia que tiene este principio en la conciliación, que se recomienda que durante el inicio de la audiencia, y también en las reuniones por separado, se mencione claramente a las partes sobre lo que ello significa. Vale recordar, así, que existen casos en la legislación comparada donde se exige la suscripción de un convenio de confidencialidad por las partes, que incluso protejan al conciliador de ser llamado a un proceso judicial. ${ }^{.1}$

\subsubsection{Excepciones al principio de confidencialidad}

Como toda regla que tiene su excepción, en la confidencialidad se aprecia el caso de aquellas situaciones en las cuales el conciliador, durante el desarrollo del procedimiento conciliatorio, toma conocimiento de determinados situaciones que configuran hechos delictivos.

Frente a una cuestión de esta naturaleza, la doctrina y legislación comparada coincide en señalar que el conciliador tiene el deber de dar a conocer estos hechos delictivos a las autoridades correspondientes.

Los problemas surgen cuando se intenta definir cuáles son los hechos delictivos que el conciliador debe poner en conocimiento de las autoridades. ¿¿Deben ser todos los hechos delictivos?, ¿¿debe discriminarse entre delitos graves o delitos leves?

Frente a ello creemos que la excepción a la confidencialidad debe manejarse con sumo cuidado, por lo cual sólo cuando el conciliador se encuentre ante delitos graves debería informar a las autoridades. En este sentido, nuestra opinión sigue la orientación de otras legislaciones,

10 Roque Caivano. op. cit. p. 135

11 Nos referimos al caso de Argentina y de varios estados de los Estados Unidos de América. 
las cuales, como en el caso argentino, señala que las excepciones a la confidencialidad pueden admitirse en dos casos: a) comisión de un delito grave; b) violencia contra un menor.

Existen otras situaciones en las que se establece que será admisible la excepción, si se dan algunos de los siguientes supuestos:

1) peligro inminente de daño corporal o muerte para alguna persona involucrada o no en la mediación;

2) amenazas o prácticas de violencia física o psíquica;

3) abuso de menores;

4) conocimiento de delitos de acción pública. ${ }^{12}$

Todas estas situaciones tendrán que manejarse con extrema diligencia por parte del conciliador, ya que una apreciación errada podría generar consecuencias indeseadas. En todo caso, el criterio que debería guiar a los conciliadores es que si su labor no puede mejorar la situación de las partes, por lo menos no debe empeorarla. ${ }^{13}$

A partir de lo señalado podemos hacer referencia al tratamiento normativo que, en nuestro país, hace la Ley y el Reglamento. En este sentido el artículo $8^{\circ}$ de la Ley establece que «quienes participan en la conciliación deben mantener reserva de lo actuado. Nada de lo que diga tendrá valor probatorio». De lo cual se desprende que se ha determinado que este deber de confidencialidad incluye además del conciliador a toda persona que participe del procedimiento conciliatorio. Por lo cual las partes que están presentes durante la audiencia, incluso el abogado del centro, verificador de la legalidad, si es que tuvo acceso a información reservada, también tendrán que ceñirse a esta prohibición.

Por otro lado, de lo contenido en el artículo $8^{\circ}$ se evidencia que en dicha norma no se ha establecido las excepciones a este principio, con lo cual podría suponerse que el legislador, para el caso peruano, no creyó conveniente hacer esta mención, con las consecuencias inadecuadas que ello podría significar. Sin embargo, el artículo $8^{\circ}$ del Reglamento se encarga de establecer las excepciones cuando en su segundo

12 Norma López Faura. "La confidencialidad en el proceso de mediación». En: Revista La Ley 1997-E, Buenos Aires, 1997, p. 1548

13 Norma López Faura. Op. cit. p. 1547 
párrafo establece: "Constituyen excepciones a la regla de la confidencialidad el conocimiento en el procedimiento de conciliación de la inminente realización de un delito, o ante uno ya consumado. En estos casos, el conciliador debe poner el hecho en conocimiento de las autoridades pertinentes".

Frente a ello debemos efectuar dos comentarios. En primer lugar, consideramos inapropiado que a través de una norma reglamentaria se hayan establecido las excepciones al principio de confidencialidad. Creemos que estas debieron estar señaladas en la propia Ley y no en una norma de menor categoría, que por su propia naturaleza no puede ir más allá de lo que la norma superior -en este caso la Ley- ha establecido.

En segundo lugar, el Reglamento no hace ninguna distinción y señala que el conciliador debe informar ante las autoridades pertinentes cuando conoce de un delito o de su inminente realización. Con lo cual el margen de acción del conciliador estará bastante limitado, ya que si conoce de un delito leve o de poca trascendencia social, igualmente tendrá que denunciar, afectando con ello incluso a las partes que quisieran llegar a un acuerdo. ${ }^{14}$

\subsection{Principio de simetría de poder o empoderamiento}

Este principio no ha sido recogido en la Ley de Conciliación, siendo importante en realidades como la nuestra donde las diferencias de toda índole son comunes entre los ciudadanos.

Puede ser definido como las actividades que lleva a cabo el conciliador para dar poder o autoridad a la parte más débil durante el procedimiento conciliatorio. Se parte del supuesto de que es necesario que haya una igualdad de fuerzas entre los participantes en la conciliación, ya que ello facilitará una influencia mutua donde una de las partes no pueda imponer a la otra un acuerdo insatisfactorio, que no se sostendrá en el curso del tiempo. ${ }^{15}$

Esta ayuda que despliega el conciliador deberá realizarse con sumo cuidado, ya que una intervención indebida podría afectar su imagen de

15 Christopher Moore. Op. cit. p. 73 
imparcialidad, con lo cual todo el esfuerzo realizado para generar la necesaria cooperación entre las partes podría venirse abajo. En este sentido se diferencia entre aquel conciliador que realiza intervenciones que ayudan a reconocer, organizar y agrupar el poder de una de las partes, y aquel conciliador que convirtiéndose en defensor, colabora en la generación de un nuevo poder.

Este principio, si bien no ha sido recogido en la legislación sobre conciliación, tiene recepción normativa en el Reglamento de la Ley que faculta a las Defensorías del Niño y Adolescente a realizar conciliaciones extrajudiciales, con valor de título de ejecución (Decreto Supremo 006-99-PROMUDEH), cuando en su artículo $3^{\circ}$, en su segundo párrafo, establece que «el conciliador de la Defensoría del Niño y Adolescente acorde con el principio de empoderamiento, evitará los desbalances de poder existentes entre las partes en conflicto con el fin de fomentar una discusión justa y equitativa, respetando el principio de imparcialidad».

Cabe también señalar que el Código Procesal Civil, en el artículo VI del Título Preliminar recoge el principio de socialización del proceso que, en palabras de Monroy recoge la tesis de la igualdad de las partes en el proceso judicial, por lo cual «un juez no sólo tendrá la oportunidad de expedir una sentencia justa, sino que además podrá impedir que la desigualdad en que las partes concurran al proceso sea un factor determinante para que los actos procesales o la decisión final sea un acto que repugne al valor justicia» ${ }^{16}$.

\subsection{Principio de la buena fe}

Tiene que ver con la actuación de las partes durante el procedimiento conciliatorio, en el sentido de un comportamiento adecuado y acorde a los fines de la conciliación. En este sentido en el Reglamento se señala que por este principio "se entiende como la necesidad de que las partes procedan de manera honesta y leal».

Se señala que este principio no sólo involucra a las partes durante la audiencia sino también a toda persona que participa de la audiencia, 
como sería el caso de abogados o asesores y representantes. Lo cual tiene sentido en la medida que lo que se espera de las personas que intervienen en el procedimiento conciliatorio es una debida actuación que no signifique un aprovechamiento indebido o de mala fe de la conciliación.

También se señala que la buena fe tendría que ver con la forma como el conciliador y/o el centro del conciliador dan a conocer sus servicios a los ciudadanos que recurren a sus servicios. Es decir, brindar información transparente sobre lo más conveniente para los intereses del solicitante, sin buscar un provecho personal o institucional.

\subsection{Principio de economía}

Este principio está definido en el Reglamento como un medio dirigido a eliminar el tiempo que demandaría a las partes al involucrarse en un proceso judicial, ahorrando los costos de dicho proceso. Al respecto, cabe precisar que este principio nos parece muy pertinente a las características del procedimiento civil, donde se dirige al ahorro de tiempo, gasto y esfuerzo. ${ }^{17}$

Situación radicalmente distinta en el caso de la conciliación, donde por sus propias características, lo que se quiere es un acuerdo justo, duradero y satisfactorio para las partes, lo cual no necesariamente implica que se busque un ahorro de tiempo, costo o esfuerzo. Es más, creemos que existen innumerables situaciones en que, por la propia naturaleza de la materia del conflicto, será necesario que las partes y el conciliador dediquen un tiempo y esfuerzo mayor, por lo que en la medida que voluntariamente así lo consideren las partes, no habrá mayores inconvenientes para que la audiencia se siga desarrollando en más de una sesión.

\subsection{Principio de celeridad}

Al igual que el principio de economía nos encontramos ante un caso donde el legislador ha pretendido aplicar un principio del proceso 
civil a la conciliación, y donde por las mismas razones expuestas anteriormente creemos que no resulta pertinente hablar de celeridad como un criterio orientador para la figura conciliatoria.

Como bien se sostiene, la celeridad, entendida como la solución pronta y rápida del conflicto, es más bien una característica de la conciliación, que debe ser entendida flexiblemente por los usuarios de este procedimiento, ya que una aplicación estricta podría desvirtuar sus fines.

\subsection{Veracidad y legalidad}

Ambos son criterios necesarios para que la conciliación sea llevada a cabo adecuadamente. Mientras que en el caso de la veracidad nos encontramos ante una garantía que necesariamente debe ser cumplida por las partes y por el conciliador, en el caso de la legalidad se refiere a que el acuerdo, al que eventualmente arriben las partes, tendrá que ser con pleno respeto por el ordenamiento jurídico.

En el caso de la veracidad, la información que las partes brinden sobre el conflicto durante el desarrollo de la audiencia deberá ser fiel reflejo de la realidad, sin que ello quiera decir que el conciliador deba ingresar a evaluar si están diciendo la verdad o no. De lo que se trata es que durante la manifestación que hagan los participantes de la audiencia, se ciñan a lo que ellos consideren como información cierta, debiendo el conciliador advertir si se encuentra ante información imprecisa o inexacta.

En el principio de legalidad, le corresponde al conciliador asegurarse que el acuerdo total o parcial al que las partes puedan suscribir, no colisione con alguna norma legal, para lo cual podrá recurrir a la asistencia especializada del abogado del centro que cumple la función de verificador de la legalidad. 